\title{
A Novel Process for the Production of Penitrem Mycotoxins by Submerged Fermentation of Penicillium nigricans
}

\author{
By P. G. MANTLE, ${ }^{*}$ I. LAWS, M. J. L. TAN AND M. TIZARD \\ Department of Biochemistry, Imperial College, London $S W 72 A Z, U K$
}

(Received 30 November 1983; revised 27 January 1984)

\begin{abstract}
A strain of Penicillium nigricans, which produces both the antifungal antibiotic griseofulvin and tremorgenic penitrem mycotoxins concurrently in static liquid culture, also elaborated both metabolites in submerged culture when stimulated by calcium chloride to sporulate. Maximum yield of penitrems $\left(60 \mathrm{mg} \mathrm{l}^{-1}\right)$ occurred within $5 \mathrm{~d}$ in a 601 stirred fermenter, thus constituting the first significant process for penitrem production in submerged culture.
\end{abstract}

\section{INTRODUCTION}

A group of tremorgenic mycotoxins, the penitrems, are elaborated by several penicillia (listed by Mantle \& Penny, 1981) though several of these fungi (Penicillium cyclopium, $P$. palitans and $P$. verrucosum var. cyclopium) should now be classified as synonyms under $P$. crustosum Thom (Pitt, 1979).

Penitrem A has been the natural cause of tremor and incoordination in dogs in the USA, and was a strong candidate as the causal agent of the incoordination syndrome known as ryegrass staggers in New Zealand (Mantle \& Penny, 1981) until more recently supplanted by the lolitrem neurotoxins elaborated in endophyte-infected ryegrass (Fletcher \& Harvey, 1981; Gallagher et al., 1981). It also bears close structural similarity to the paspalinines which are tremorgenic metabolites of Claviceps paspali causing paspalum staggers in cattle grazing ergotized Paspalum (Mantle et al., 1978b). All structural and biosynthetic studies on these compounds (de Jesus et al., 1983; Kyriakidis et al., 1981; Mantle et al., 1983) have used cultures grown on the surface of liquid media, since the mycotoxins have not been produced when mycelia are grown in submerged culture (Wagener et al., 1980).

A brief exploration of tremorgenic soil-borne moulds in England (Mantle et al., 1978a) revealed a unique strain of Penicillium nigricans which produced penitrem A when grown on Czapek Dox broth supplemented with yeast extract. The fungus also produced griseofulvin, a biochemical feature consistent with identification of the organism on morphological criteria as $P$. nigricans, one of the first species found to elaborate griseofulvin. While the penitrems and griseofulvin are biosynthetically distinct, the former being indolic- and isoprene-derived and the latter a polyketide, inclusion of chlorine in the molecule is a characteristic which griseofulvin has in common with several penitrems including the most abundant penitrem A. Penicillium nigricans is as ineffectual in submerged culture as other penitrem-producing penicillia when grown in a Czapek Dox yeast extract medium, but the present report demonstrates that it is sensitive to the sporulation-inducing effect of calcium chloride and concomitantly in submerged culture elaborates penitrems $\mathrm{A}, \mathrm{C}$ and $\mathrm{E}$ in significant yield.

\section{METHODS}

Organism. The strain of Penicillium nigricans Bainer ex Thom used in this study was originally isolated from soil in Devon, England (Mantle et al., 1978a). The fungus is deposited at the Commonwealth Mycological Institute, Kew (IMI 228669).

Media. The medium used for laboratory scale cultures was a Czapek Dox broth supplemented with yeast extract, $\mathrm{pH} 7 \cdot 3$, containing ( $\mathrm{g}^{-1}$ in distilled water): sucrose, $30 ; \mathrm{NaNO}_{3}, 3 ; \mathrm{K}_{2} \mathrm{HPO}_{4}, 1 ; \mathrm{MgSO}_{4} .7 \mathrm{H}_{2} \mathrm{O}, 0 \cdot 5$; $\mathrm{KCl}, 0.5 ; \mathrm{FeSO}_{4} .7 \mathrm{H}_{2} \mathrm{O}, 0.01$; yeast extract (Difco), 5. For submerged culture, where indicated, the nutrient medium was supplemented with $\mathrm{CaCl}_{2} \cdot 2 \mathrm{H}_{2} \mathrm{O}\left(20 \mathrm{~g}^{-1}\right)$ to induce sporulation. 
Culture conditions. Cultures were maintained on potato dextrose agar and spore inoculum was prepared from slope cultures grown at $27^{\circ} \mathrm{C}$ for $7 \mathrm{~d}$.

Static flask cultures. Erlenmeyer flasks ( $500 \mathrm{ml}$, including some with baffles) containing $100 \mathrm{ml}$ (or $50 \mathrm{ml}$ in baffled flasks) medium were sterilized at $121^{\circ} \mathrm{C}$ for $20 \mathrm{~min}$. A baffled flask was seeded with dry conidia and hyphae transferred from a slope culture and incubated at $27^{\circ} \mathrm{C}$ for $20 \mathrm{~h}$ on a rotary shaker (200 r.p.m., $10 \mathrm{~cm}$ eccentric throw). A sample of shaken culture $(2 \mathrm{ml})$ was transferred to each flask containing $100 \mathrm{ml}$ medium which was then incubated statically at $27^{\circ} \mathrm{C}$ for up to $14 \mathrm{~d}$.

Shaken flask cultures. The preliminary phase of the protocol for static cultures (above) was followed, providing a $20 \mathrm{~h}$ seed stage culture in baffled flasks. Seed stage culture $(4 \mathrm{ml})$ was transferred to conventional flasks containing $100 \mathrm{ml}$ medium (with or without $\mathrm{CaCl}_{2}$ ) and the flasks were incubated on a rotary shaker at $27^{\circ} \mathrm{C}$ for up to $7 \mathrm{~d}$.

Stirred fermenter. The vessel used was a stainless steel 601 fermenter of conventional design (Banks et al., 1974; Day et al., 1980). Temperature control was achieved by the automatically regulated flow of cooling water through the fermenter jacket. Culture aeration was provided by sparging air $\left(601 \mathrm{~min}^{-1}\right)$ through a ring sparger into the culture fluid, which was agitated by means of a single disc turbine impeller rotating at 367 r.p.m.

The medium, differing slightly in detail from that used for laboratory scale cultures, contained $\left(\mathrm{g}^{-1}\right.$ in distilled water): sucrose, $30 ; \mathrm{NaNO}_{3}, 2 ; \mathrm{KH}_{2} \mathrm{PO}_{4}, 1 ; \mathrm{MgSO}_{4} .7 \mathrm{H}_{2} \mathrm{O}, 0.5 ; \mathrm{KCl}, 0.5 ; \mathrm{FeSO}_{4} .7 \mathrm{H}_{2} \mathrm{O}, 0.01$; yeast extract (Lab M), 5; $\mathrm{CaCl}_{2}$ (anhydrous), $15 \cdot 1$; polypropylene glycol antifoam (P2000), $0 \cdot 1 \mathrm{ml} \mathrm{l}^{-1}$. Medium (55 l) was prepared in situ and the $\mathrm{pH}$ was adjusted from 4.7 to 6.0 by addition to $\mathrm{NaOH}$. Medium and fermenter were sterilized at $121^{\circ} \mathrm{C}$ for $20 \mathrm{~min}$ by live-steam injection. Allowance was made for condensate subsequently formed during sterilization, the final post-sterilization volume of the medium being 601 .

The fermenter was inoculated with 21 secondary seed stage culture. This was obtained from a $20 \mathrm{~h}$ primary seed culture ( $50 \mathrm{ml}$ medium in baffled flasks), which had been transferred to each of two 41 flasks containing 11 unsupplemented medium, which were then incubated on the rotary shaker for a further $20 \mathrm{~h}$ at $27^{\circ} \mathrm{C}$.

Antifoam was added after $12 \mathrm{~h}$ fermentation to control foaming. The vessel was monitored for contamination daily throughout the fermentation by microscopic examination of samples and culture at $24^{\circ} \mathrm{C}$ and $37^{\circ} \mathrm{C}$ on media favourable for bacterial or fungal contaminants.

Analytical procedures. Samples for analysis consisted of the mycelium, filtered through Whatman no. 1 paper, from flask cultures or from $300 \mathrm{ml}$ volumes taken from the fermenter at intervals, and the filtrate.

(i) Mycelial dry weight. Mycelium from at least $100 \mathrm{ml}$ culture, homogenized (where appropriate) or suspended in distilled water, was freeze-dried to constant weight.

(ii) Sporulation. A few ml of culture were coarsely filtered through cotton wool to remove hyphae. The spore content of the broth, suitably diluted where necessary, was measured using a haemocytometer.

(iii) Product extraction. Freeze-dried mycelium was extracted exhaustively with acetone $\left(2 \times 200 \mathrm{ml} \mathrm{g}^{-1}\right)$ over $24 \mathrm{~h}$ and the combined extracts taken to dryness. Culture filtrate was extracted by vigorous shaking with chloroform $(2 \times$ equal volume $)$ and the combined extracts taken to dryness.

(iv) Griseofulvin. Mycelial or culture filtrate extracts were taken up in an appropriate volume of methanol and $20 \mu \mathrm{l}$ samples were injected into an isocratic HPLC system using an ODS ultrasphere ( $5 \mu \mathrm{m}$ particle size) reversed phase column $(250 \times 4.2 \mathrm{~mm})$ linked to a Perkin Elmer $1000 \mathrm{M}$ fluorimeter operating at excitation wavelength $340 \mathrm{~nm}$ and emission wavelength $450 \mathrm{~nm}$, close to the maxima for griseofulvin ( $\operatorname{Ex}_{\max } 325 \mathrm{~nm}, \operatorname{Em}_{\max } 450 \mathrm{~nm}$ ). The mobile phase was methanol $\left(1 \mathrm{ml} \mathrm{min}^{-1}\right)$. The equipment was calibrated using $20 \mu \mathrm{l}$ amounts of standard methanolic solutions in the range $100-700 \mu \mathrm{g}$ griseofulvin $\mathrm{ml}^{-1}(2-12 \mu \mathrm{g}$ per injection), the fluorescence signal being quantified as the height of a peak traced on a chart recorder. This gave, over the range used, a linear standard curve from which the results of sample analysis could be quantified.

(v) Penitrems. Methanolic extracts were assayed by the method of Hou et al. (1970), which involves heating methanolic extract with $\mathrm{H}_{2} \mathrm{SO}_{4}$ and measuring the blue colour spectrophotometrically at $630 \mathrm{~nm}$ with reference to a penitrem A standard. Values for total penitrems are therefore expressed as for penitrem A.

(vi) Identification of metabolites. The fluorescent substance in the methanolic extracts, co-chromatographing with authentic griseofulvin in HPLC, was shown also to co-chromatograph in TLC (Polygram SIL G ${ }_{254}$, CamLab) developed in chloroform/acetone $(93: 7)$ and visualized under UV light $(350 \mathrm{~nm})$. The same chromatograms, sprayed with $5 \%(\mathrm{w} / \mathrm{v}) \mathrm{FeCl}_{3}$ in $n$-butanol and gently heated, revealed the characteristic green colours, particularly in regions co-chromatographing with authentic penitrems $\mathrm{A}$ and $\mathrm{E}$, and the pink colour characteristic of penitrem C. Electron impact and fast atom bombardment mass spectrometry of appropriate fractions eluted from chromatograms showed the ions to be identical to those of authentic griseofulvin and characteristic of penitrems $A$ and $\mathrm{E}$ (Fellows et al., 1981).

\section{RESULTS}

Within $1 \mathrm{~d}$ of inoculation of stationary cultures a white pellicle was established. The mycelium thickened to give a greenish-white sporing mat of maximum dry weight within $5 \mathrm{~d}$ (Fig. 1). 


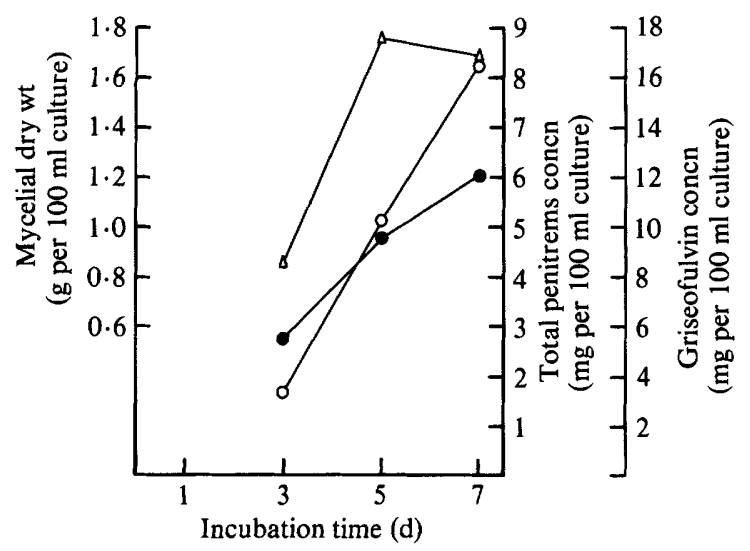

Fig. 1. Progress of static fermentation of Penicillium nigricans on Czapek Dox/yeast extract broth. $\Delta$, Mycelial dry weight; $\bigcirc$, griseofulvin yield; $\bigcirc$, penitrem yield. Sporulation occurred but was not measured.

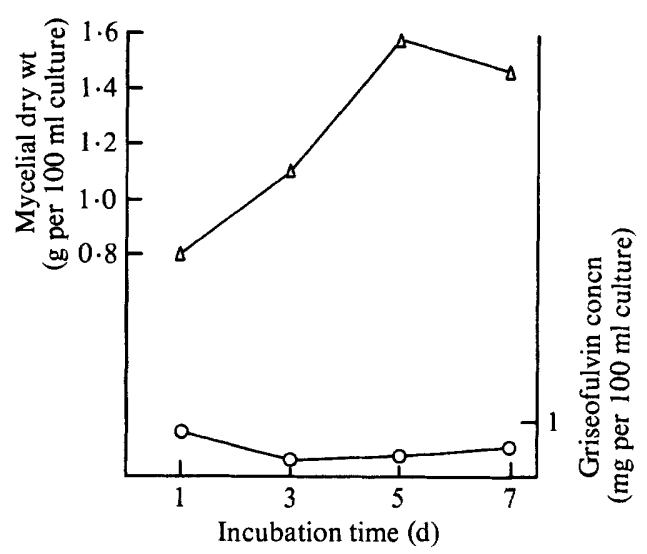

Fig. 2. Progress of shaken flask fermentation of Penicillium nigricans in Czapek Dox/yeast extract broth. $\triangle$, Mycelial dry weight; $O$, griseofulvin yield.

Biosynthesis of griseofulvin and penitrems commenced before biomass accumulation was complete. Dry weight was generally near maximum at about $7 \mathrm{~d}$ and at $14 \mathrm{~d}$ a metabolite weight ratio of $\sim 2: 1$ was achieved for griseofulvin and penitrems, respectively. In shaken flask culture in the same medium biomass accumulated over a similar period but there was no sporulation. A small amount of griseofulvin was produced but penitrems could not be detected (Fig. 2). However, when the medium was supplemented with $\mathrm{CaCl}_{2}$ profuse sporulation was initiated within the first day of submerged fermentation, the subsequent yield of griseofulvin improved and penitrems accumulated to the significant yield of $0.9 \mathrm{mg}$ per $100 \mathrm{ml}$ medium (Fig. 3).

When extended to the 601 scale in a stirred fermenter (Fig. 4) the most notable consequence was a sixfold increase in the yield of penitrems while griseofulvin yield remained at $\sim 1.5 \mathrm{mg}$ per $100 \mathrm{ml}$ medium. Only $2 \mathrm{~d}$ were required for biomass to reach a maximum value, while the fungus sporulated profusely, giving the culture a green colour. The secondary metabolites were produced concurrently in an idiophase which was chronologically distinct from the trophophase and was associated with a steady rise in the $\mathrm{pH}$ of the broth. The penitrems remained principally cell associated while a significant proportion of the griseofulvin was released into the broth (Table 1). In a stirred fermenter, therefore, a process in which sporulation was stimulated by calcium ions accumulated total penitrem in amounts similar to when the fungus grows and sporulates in static culture, though apparently at the expense of a reduction in the griseofulvin yield of an order of magnitude. 


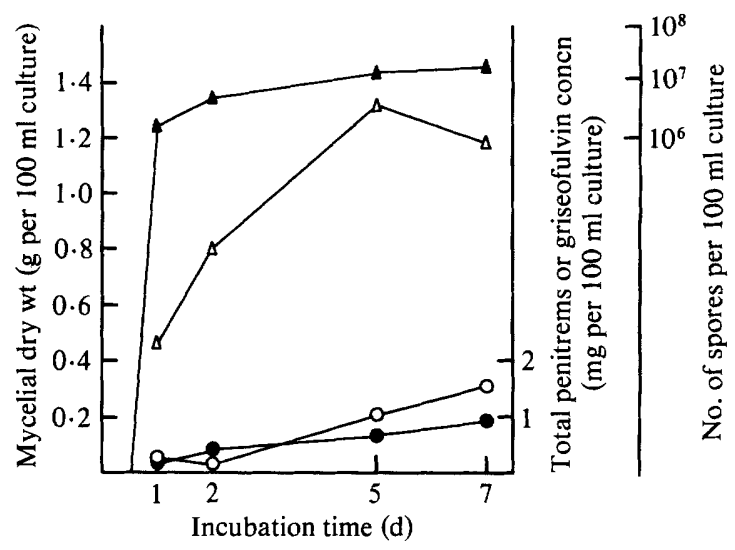

Fig. 3. Progress of shaken flask fermentation of Penicillium nigricans in Czapek Dox/yeast extract broth plus $\mathrm{CaCl}_{2} . \Delta$, Mycelial dry weight; $\Delta$, sporulation; $O$, griseofulvin yield; $\bullet$, penitrem yield.

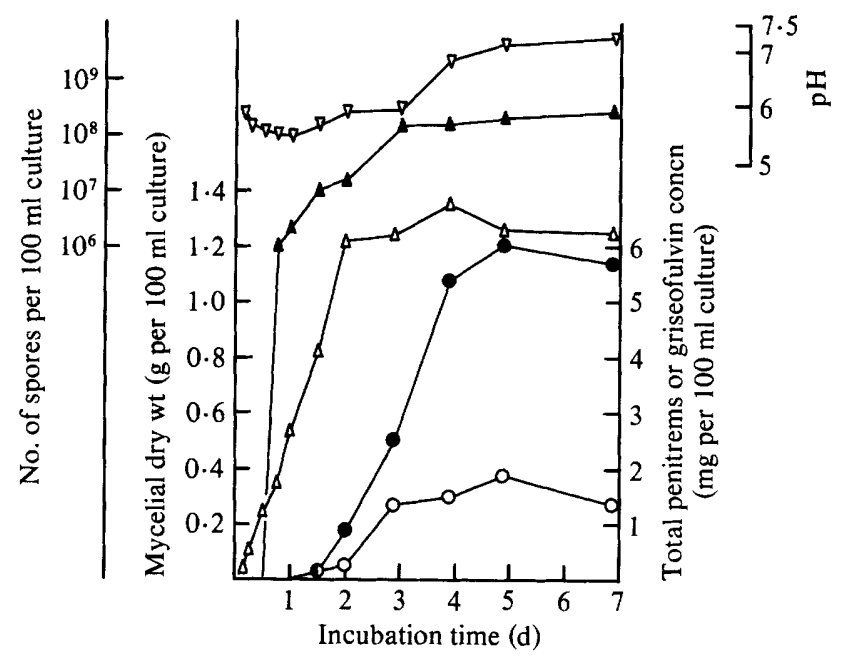

Fig. 4. Progress of stirred 601 fermentation of Penicillium nigricans in Czapek Dox/yeast extract broth plus $\mathrm{CaCl}_{2} . \Delta$, Mycelial dry weight; $\boldsymbol{\Lambda}$, sporulation; $\nabla$, broth $\mathrm{pH} ; \mathrm{O}$, griseofulvin yield; $\boldsymbol{\bullet}$, penitrem yield.

Table 1. Distribution of griseofulvin and penitrems between the mycelium and the culture filtrate in a 60 l fermentation of Penicillium nigricans

\begin{tabular}{ccccc}
$\begin{array}{c}\text { Fermentation } \\
\text { time elapsed } \\
\text { (h) }\end{array}$ & $\overbrace{\begin{array}{c}\text { Culture } \\
\text { filtrate }\end{array}}^{\begin{array}{c}\text { Griseofulvin } \\
\text { Mycelium }\end{array}}$ & \multicolumn{2}{c}{$\begin{array}{c}\text { Culture } \\
\text { filtrate }\end{array}$} & $\begin{array}{c}\text { Mycelium } \\
\text { (mg per 100 ml culture) }\end{array}$ \\
6 & 0 & 0 & 0 & 0 \\
12 & 0 & $<0.001$ & 0 & 0 \\
18 & 0 & $<0.001$ & 0 & 0.002 \\
24 & 0.04 & 0.01 & $<0.001$ & 0.01 \\
36 & 0.05 & 0.10 & 0.04 & 0.12 \\
48 & 0.06 & 0.18 & 0.09 & 0.79 \\
69 & 0.57 & 0.76 & 0.07 & 2.43 \\
93 & 0.48 & 1.00 & 0.07 & 5.31 \\
117 & 0.76 & 1.11 & 0.24 & 5.77 \\
165 & 0.63 & 0.74 & 0.19 & 5.52
\end{tabular}




\section{DISCUSSION}

The yield of penitrems obtained in the 601 scale is comparable to that usually obtained in surface cultures of Penicillium crustosum (Mantle et al., 1983) though only about one-fifth of the best yields $(\sim 3 \%$, w/w) obtained with this fungus (Mantle et al., 1978b). The opportunity now available to study the dynamics and control of penitrem production is emphasized by the clear chronological separation of the idiophase from the trophophase, suggesting, therefore, that control may be exercised through growth-limiting factors. However, it seems unlikely that the fermentation would be amenable to significant exploration in continuous culture. Whereas griseofulvin and the penitrems appear to be biosynthesized concurrently there is some evidence that optimum conditions for one may not be ideal for the other. The use of calcium ions to stimulate sporulation of certain penicillia is a well established technique (Foster et al., 1945) and, apposite to the present instance, has previously been successfully exploited in the large scale production of another tremorgenic mycotoxin, verruculogen, by Penicillium simplicissimum (Day et al., 1980). The yield of verruculogen was similar to that presently described for penitrems. Unfortunately, strains of $P$. crustosum giving high yields of penitrem in static culture, associated with considerable sporulation, have appeared insensitive to calcium ions in submerged culture (Day, 1980). However, the convenient sporulation response of $P$. nigricans and the concomitant biosynthesis of the penitrem metabolites gives an added dimension requiring an understanding of the mechanism of calcium-induced sporulation in the penicillia, in which there has been a recent resurgence of interest (Pitt \& Poole, 1981; Ugalde \& Pitt, 1983).

We wish to thank the Science and Engineering Research Council for a Research Studentship (I. L.), the technical staff of Imperial Biotechnology Ltd for pilot plant facilities, and J. Bilton and Miss J. Oates for E. I. and FAB mass spectrometry.

\section{REFERENCES}

Banks, G. T., Mantle, P. G. \& Szczyrbak, C. A. (1974). Large-scale production of clavine alkaloids by Claviceps fusiformis. Journal of General Microbiology 82, 345-361.

DAY, J. B. (1980). Tremorgenic mycotoxins and natural staggers syndromes. $\mathrm{PhD}$ thesis, University of London.

Day, J. B., Mantle, P. G. \& Shaw, B. I. (1980). Production of verruculogen by Penicillium estinogenum in stirred fermenters. Journal of General Microbiology $117,405-410$.

Fellows, P. A., Kyriakidis, N., Mantle, P. G. \& WAIGHT, E. S. (1981). Electron impact mass spectra of penitrem A, some derivatives and its analogues. Organic Mass Spectrometry 16, 403-404.

Fletcher, L. R. \& Harvey, I. C. (1981). An association of a Lolium endophyte with ryegrass staggers. New Zealand Veterinary Journal 29, 185186.

Foster, J. W., MCDANIEL, L. E., WoOdRufF, H. B. \& STOKES, J. L. (1945). Microbiological aspects of penicillin-conidiospore formation in submerged cultures of Penicillium notatum. Journal of Bacteriology 50, 365-368.

Gallagher, R. T., White, E. P. \& Mortimer, P. H. (1981). Ryegrass staggers: isolation of potent neurotoxins Lolitrem A and Lolitrem B from staggers producing pastures. New Zealand Veterinary Journal 29, 189-190.

Hou, C. T., Ciegler, A. \& Hesseltine, C. W. (1970). Tremorgenic toxins from penicillia. Colorimetric determination of tremortins A and B. Analytical Biochemistry 37, 422-428. de Jesus, A. E., Steyn, P. S., Van Heerden, F. R., VleggaAR, R., Wessels, P. L. \& Hull, W. E. (1983). Tremorgenic mycotoxins from $P$. crustosum: isolation of penitrems $\mathrm{A}-\mathrm{F}$ and the structural elucidation and absolute configuration of penitrem A. Journal of the Chemical Society, 18471856.

KYRIaKidis, N., Waight, E. S., Day, J. B. \& Mantle, P. G. (1981). Novel metabolites from Penicillium crustosum, including penitrem E, a tremorgenic mycotoxin. Applied and Environmental Microbiology 42, 61-62.

Mantle, P. G. \& Penny, R. H. C. (1981). Tremorgenic mycotoxins and neurological disorders - a review. Veterinary Annual 21, 51-62.

Mantle, P. G., Day, J. B., Haigh, C. R. \& Penny, R. H. C. $(1978 a)$. Tremorgenic mycotoxins and inco-ordination syndromes. Veterinary Record 103, 403.

Mantle, P. G., Mortimer, P. H. \& White, E. P. $(1978 b)$. Mycotoxic tremorgens of Claviceps paspali and Penicillium cyclopium: a comparative study of effects on sheep and cattle in relation to natural staggers syndromes. Research in Veterinary Science 24, 49-56.

Mantle, P. G., Perera, K. P. W. C., Maishman, M. J. \& MUNDY, G. R. (1983). Biosynthesis of penitrems and roquefortine by Penicillium crustosum. Applied and Environmental Microbiology 45, 1486-1490.

PItT, J. I. (1979). Penicillium crustosum and $P$. simplicissimum, the correct names for two common species producing tremorgenic mycotoxins. Mycologia 71, 1166-1177. 
PITT, D. \& Poole, P. C. (1981). Calcium-induced condiation in Penicillium notatum in submerged culture. Transactions of the British Mycological Society 76, 219-230.

UGALDE, U. \& PITt, D. (1983). Morphology and calcium-induced conidiation of Penicillium cyclopium in submerged culture. Transactions of the British Mycological Society 80, 319-325.

WAGENER, R. E., DAvis, N. D. \& Diener, U. L. (1980). Penitrem $A$ and roquefortine production by Penicillium commune. Applied and Environmental Microbiology 39, 882-887. 